\title{
MELHORIA EM PROCESSO DE MONTAGEM COM REDUÇÃO DE CONSUMO DE MATÉRIA-PRIMA EM MONTADORA AUTOMOBILÍSTICA
}

\section{PROCESS IMPROVEMENT ASSOCIATED WITH DECREASED CONSUMPTION OF RAW MATERIAL IN AN AUTOMOTIVE COMPANY}

\author{
Cleisson Soares Lima ${ }^{1}$; Fabrício Palma Braga ${ }^{2}$;Wislei Riuper Osório ${ }^{3}$ \\ ${ }^{1}$ Honda Automóveis Brasil - HAB - Sumaré, SP; Brasil, Desenvolvimento de Projetos e Pesquisa \\ cleisson_lima@honda.com.br \\ ${ }^{2}$ Faculdade Network, Campus Nova Odessa, SP, Brasil e Universidade de Campinas, UNICAMP - \\ Campinas,SP \\ fbraga@honda.com.br \\ ${ }^{3}$ Faculdade Network, Campus Nova Odessa, SP, Brasil e Universidade de Campinas, UNICAMP - \\ Campinas,SP \\ adm@nwk.edu.br
}

\begin{abstract}
Resumo
O presente artigo objetiva mostrar um estudo de redução de custos com material secundário denominado Terolan ${ }^{\circledR}$ quando na modificação dos bicos de aplicação deste material, que é utilizado pelo departamento de pintura durante a realização de um de seus processos produtivos dentro de uma das mais conceituadas montadoras da Região Metropolitana de Campinas. Resultados permitem observar que cerca de $R \$ 650$ mil ao ano foram economizados quando na produção de carrocerias de dois diferentes tipos de automóveis. Uma redução em torno de $60 \%$ foi obtida e atribuída ao menor consumo de material de selagem de carroceria devido às modificações realizadas nos dispositivos de aplicação do cordão de material. Além disso, os autores chamam a atenção para que sejam tomadas opiniões dos colaboradores de produção e que esses sejam valorizados como capital humano para que se atinjam maiores vantagens competitivas.
\end{abstract}

Palavras-chave: redução de custo; matéria-prima; carroceria; produção automotiva.

\section{Introdução}

O processo de globalização trouxe uma forte dinâmica de competitividade em diversos setores. No industrial fomenta-se uma indução às grandes transformações, forçando com que as empresas procurem atender ao mercado consumidor oferecendo qualidade agregada à considerável redução nos custos de produção, além da satisfação dos clientes (SLACK, 2002; SLACK ET AL, 2002, OSÓRIO ET AL, 2004; LIMA; OSÓRIO, 2008). Desde a revolução industrial o mundo foi 
transformado, marcando o início da produção industrial moderna (KUNIGAMI; OSÓRIO, 2009). Ao longo do tempo as empresas têm variado muito em como administrar o seu trabalho e em como produzir seus produtos para atender ao mercado. A competitividade no campo da administração de produção de veículos, nem sempre é de conhecimento dos consumidores, o número de processos dos são necessários, desde a matéria-prima até a efetiva confecção de uma carroceria (white body), e até se tornarem no produto final para consumo. Nem mesmo a importância e o "peso" que possui os processos internos produtivos, onde uma simples falha ocasionada por qualquer um desses, pode influenciar e comprometer toda a confiabilidade da marca e do modelo.

O cenário automobilístico brasileiro vem se tornando cada vez mais competitivo, devido ao surgimento de novas montadoras com níveis tecnológicos e de automação cada vez mais avançados (BRAGA et al, 2008). Para agravar a situação, recentemente, não só no setor automobilístico, a tendência econômica mundial tem afetado significativamente as margens de lucro. Com isso, particularmente pátios de montadoras e concessionárias de automóveis encontram-se com níveis de estocagem jamais atingidos. Toda a economia está afetada e para sobreviver a essa crise, recursos tecnológicos associados às novas técnicas de administração, filosofias de trabalho podem propiciam níveis de produtividade um pouco melhor que aqueles efetivamente obtidos no geral. Acredita-se que a capacidade de renovação e de desenvolvimento de produtos tem sido considerada, cada vez mais, elemento de competitividade entre as montadoras automobilísticas (CERRA; MAIA, 2006).

Sabe-se que uma montadora de automóveis é consistida basicamente por pequenos estoques de matéria-prima, estamparia, soldagem, montagem de carroceria, pintura e montagem de componentes finais, que trabalham relativamente em sincronismo, sempre no intuito de redução de custos de produção e matéria-prima, para obtenção de melhores resultados de produtividade. A empresa estudada trata-se de uma montadora situada na Região Metropolitana de Campinas que conta com a contribuição em torno de 2500 colaboradores e produz internamente uma porcentagem das peças que compõem o automóvel, como, pára-choque, painel e seus componentes agregados (injeção plástica), estampagem de portas, capôs, porta-malas (estamparia), usinagem de carcaça de câmbio (usinagem) dentre outros em projeto e desenvolvimento. Possui ainda uma gama de componentes importados para a montagem e produção de seus veículos, mas busca a curto prazo através de parcerias com fornecedores nacionais uma verticalização (MARTINS; ALT, 2003) de seus componentes com alta qualidade e com preço acessível e mais competitivo.

O presente artigo tem como objetivo mostrar um estudo-de-caso de redução de custos com o uso e consumo do material secundário, comercialmente conhecido como Terolan ${ }^{\circledR}$, quando na modificação dos bicos de aplicação do material para os dois modelos de automóveis montados na planta em questão. 


\section{O analista e o planejamento do processo}

Ainda hoje, encontram-se inúmeras empresas sem qualquer organização ou documentação do processo que possuem. Isso tem causado um grande "estrago financeiro" às essas empresas, principalmente àquelas pequenas e médias que, tendo sido construídas e desenvolvidas pelos próprios donos, raramente tiveram a oportunidade de serem erguidas de forma organizada, com todos os processos documentados (CRUZ, 2002). Processo é a forma pela qual um conjunto de atividades cria, trabalha ou transforma insumos (entradas), agregando-lhes valor, com a finalidade de produzir bens ou serviços, com qualidade, para serem entregues a clientes (saídas), sejam eles internos ou externos (TUBINO, 1999; SLACK et al, 2002; MARTINS; ALT, 2003; CRUZ, 2002; TUBINO, 2004).

Alguns processos podem ser divididos em sub-processos. Isso tem confundido os profissionais que precisam lidar com a conceituação e com as informações pertinentes aos processos. Confundir procedimentos com processo é um erro freqüentes. Os procedimentos fazem parte através das atividades que formam o processo. Por isso é comum ouvir profissionais experientes dizerem que essa ou aquela empresa tem dezenas de processos, quando isso não é verdade. Uma empresa com um faturamento anual de dezenas de bilhões de dólares pode apresentar apenas três ou quatro processos. Assim, não é possível que uma empresa que produz uns poucos tipos de bens ou serviços tenha dezenas de processos (CRUZ, 2002; TUBINO, 1999; TUBINO, 2004). Outro erro freqüente é confundir métodos de produção com processos. Enquanto método de produção trata a técnica pela qual se produz algo, processo define a forma pela qual essa técnica é empregada.

Enfim, tratando-se tanto de método, quanto de processo, a empresa que pretende se perpetuar no mercado com uma tendência de fidelização de seus clientes, deve por intermédio de seus métodos e processos de trabalho, minimizar os custos e maximizar os resultados com satisfação total de clientes, acionistas, colaboradores e sociedade.

Existe uma tendência de mercado que consiste no desenvolvimento de atividades de externalização (MARTINS; ALT, 2003; RODRIGUES; SELLITTO, 2008) da manufatura e ou processos, onde se procuram fornecedores capazes de atender às expectativas das empresas. Isso pode resultar e produtos e ou serviços com qualidade, prazo e preço aceitáveis. Quando isso não é possível, as alternativas são: produzir o produto internamente (verticalização) (MARTINS; ALT, 2003), mudar de fornecedor, ou melhorar o desempenho do fornecedor, optando por desenvolvê-lo (PIRES, 2004, p.159). Para tal desenvolvimento são necessárias relações estreitas com poucos fornecedores, intensa comunicação entre cliente fornecedor e orientação estratégica mútua de longo prazo (CHEN et al, 2004; RODRIGUES; SELLITTO, 2008). 
Para o analista de processos, antes de qualquer outro preocupação, é preciso entender as necessidades de seus clientes, ou ainda considerando as etapas subsequentes dentr de uma mesma linha de pordução ou montagem, as atividades que serão complementadas ou adicionadas (SLACK et al, 2002). Torna-se tambpem importante ao analista de processos conhecer as reais preocupações de cada usuário envolvido pelo projeto, saber distinguir as necessidades reais das necessidades imaginárias. Seqüencialmente, o analista deve levantar e documentar os dados, o que representa um trabalho difícil de ser iniciado e completado, mas importantíssimo, pois através dele, podem ser entendidas todas as variáveis adstritas aos problemas para depois analisar o processo com base no conjunto de informações levantadas. No passo seguinte, o analista deve desenvolver uma, ou várias soluções para o problema apresentadoe por fim, devrá executar a tarefa de implantar a solução previamente analisada, discutida e escolhida pelo usuário (SLACK et al, 2002; MARTINS e LAUGENI, 2001; MOREIRA, 2002).

Embora, no passado essas atribuições eram desenvolvidas por analistas de Organização e Métodos e atualmente são realizadas em grupos de trabalho de cada seção ou departamento e supervsinao por um ou mais especialista da área, pode-se dizer que, o cerne da questão permanece o mesmo, ou seja, fazer o processo produtivo mais eficiente, mais competitivo, com preocupação com aspectos ambientais, sem abrir mão da qualidade do bem ou serviço desejado (SLACK et al, 2002; MARTINS e LAUGENI, 2001; MOREIRA, 2002; GAITHER e FRAZIER, 2004).

Lembra-se ainda que uma componente fundamental de todo e qualquer processo é o tempo de realização do processo. Essa varável coloca o processo dentro de uma perspectiva prática. Com o tempo prosionado é possível ter um prodinóstico de quando fazer, do que ser feito e para qual destino o bem ou serviço será produzido (SLACK et al, 2002; MOREIRA, 2002; GAITHER e FRAZIER, 2004). Assim, definem-se as metas mensuráveis do processo, tendo-se a dimensão do que produzir, em quais quantidades, com qual qualidade e em quanto tempo (SLACK et al, 2002).

Conhecendo-se cada um dos elementos do processo, dreciona-se esforços para documentação e melhoria cotinua do processo. Contudo, o analista deve ter a vivência no cotidiano do processo, conhecê-lo na prática, deve conhecer e entender o processo como um conjunto de atividades que devem funcionar de forma harmônica. Uma falha cometida pelos antigos analista de processo consistiu em considerar cada atividade existente como uma etapa única e independente, ou quando muito, como parte de um departamento (SLACK et al, 2002; MARTINS e LAUGENI, 2001; MOREIRA, 2002). Outra falha operacional pode estra relacionada ao desvio do foco das atenções da análise exclusivamente para as partes, sem considerar o processo. Desta forma as documentações perdem a referência de conjunto (SLACK et al, 2002). 


\subsection{A criação e inovação do analista no processo}

Considera-se ainda que o processo criativo é recente, abstrato e de difícil definição, embora existam algumas idéias e tentativas de definição (ALVES e JUNIOR, 2010). Reporta-se que tudo deu-se início com um modelo de processo criativo proposto por Graham Wallas (WALLAS, 1926; ALVES e JUNIOR, 2010), que o define como sendo um processo subconsciente do pensamento em Preparação (obtenção das informações relacionadas com o problema), Incubação (trabalho inconsciente na busca da resolução do problema), Iluminação e Verificação (atesta-se a aplicação e viabilidade da idéia), conforme recentemente descrito por Alves e Junior (2010). Depois disso, inúmeros pesquisadores propuseram modificações, evoluções ou complementações combinatórias a esse modelo ou modelos propostos subseqüentemente (ROSSMAN; 1931; OSBORN, 1953; PLSEK, 1997) até a evolução e criação do modelo do processo criativo trevo fractal concebido pelo Alberti Pascal (ALBERTINI, 2006; ALVES e JUNIOR, 2010), que descreve mais precisamente o processo aleatório da criatividade e suas variáveis, construído à atender a uma problemática de estimulação da criatividade e para a organização posterior desse processo.

Alves e Junior (2010) em recente publicação pormenorizem aspectos particulares desse modelo, e concluem em seus estudos que para a execução desse processo criativo necessita-se mais que intuição, lampejos de criação e idéias fantásticas. Atestam que nas empresas exige-se preparo e métodos para a resolução das situações do dia a dia, envolvendo investigação, análise e verificação das variáveis envolvidas, entre outras (ALVES e JUNIOR, 2010). Verificaram ainda que o processo criativo por meio do modelo criativo trevo fractal apresenta características que estimulam a criação das soluções e a busca por melhores resultados, respeitando o contexto organizacional, sem a imposição de regras e caminhos prévios para essas soluções (ALVES e JUNIOR, 2010). Outra observação muito importante apontada por Alves e Junior (2010) e deve ser destacada, consiste no fato de que as ações do processo criativo, por meio de caminhos aleatórios e sem ferramentas específicas fornecem liberdade de criação aos colaboradores, propiciando-se diversas soluções. Isso permite o estimulo ao desenvolvimento de novas maneiras de se fazer mais com menos, potencializando-se a redução de custos e a simplificação de processos, para novas utilizações dos produtos e processos (ALVES e JUNIOR, 2010).

De modo sintetizado pode-se entender o modelo de Albertini (2006), como sendo três grandes conjuntos interseccionados em atividades de metas-ações: PLANEJAR, GERAR e EXPLICITAR que estão interrelacionadas concomitantemente. Cada conjunto é constituído por subconjuntos que representam inúmeras atividades (descritas na Figura 1) que não necessariamente são interdependentes das atividades de cada um dos conjuntos maiores: Planejar, Gerar e Explicitar. 
Pode-se dizer que o modelo de Albertini (2006) foi concebido como função de um diagrama de afinidade (JIRO, 1991), sintetizando-se os resultados de uma pesquisa qualitativa em três grandes metas-ações, mencionadas anteriormente. Essas metas-ações podem ser descritas como segue (ALVES e JUNIOR, 2010):

\section{ANALISAR (Meta-ação)}

a) Ação - Avaliar o ambiente e a utilização do produto ou processo - busca exaustiva das necessidades, conceitos e informações do ambiente interno e externo, influenciando diretamente ou indiretamente no contexto de utilização do produto ou processo;

b) Ação - Identificar as formas de utilização do produto ou processo - definir as funções,serviços e as características do produto ou processo, essenciais a sua utilização, através dasexpectativas dos usuários e das restrições impostas pela sua utilização; e

c) Ação - Definir as características do processo produtivo - definir quais as características doprocesso produtivo e suas funções, proporcionando a análise das etapas.

\section{GERAR (Meta-ação)}

d) Ação - Analisar as informações sobre o produto ou processo - visa analisar a concorrência, as informações dos produtos ou processos, os produtos ou processos equivalentes, os materiais, detalhes de normas, regulamentos, etc;

e) Ação - Levantar as tendências do produto ou processo - levantar e analisar os conceitos dos produtos ou processos disponíveis no mercado e compreender os modos dos usuários na utilização desses conceitos, projetando as tendências do produto ou processo;

f) Ação - Investigar as funções (novas e tradicionais) do produto ou processo - expressar através de problemáticas de utilização (contextualização das necessidades de utilização) os serviços e funções do produto ou processo. Pode-se utilizar de frases, ditados populares, gestos, fotografias, desenhos a mão, computador (CAD), bidimensionais (2D) ou tridimensionais (3D), maquete real, virtual e imagem mental, entre outras;

g) Ação - Encontrar conceitos para pesquisar - definir do ponto de vista dos serviços e funções do produto ou processo os conceitos para os eixos de pesquisa a serem tecnicamente desenvolvidos, específicos para o produto ou processo;

h) Ação - Representar as idéias a serem pesquisadas - definir, representar e materializar as idéias em conceitos de modo formal para se comunicar, para avaliação. Pode-se utilizar frases, ditados populares, gestos, fotografias, imagem mental, desenhos a mão, computador (CAD), bidimensionais (2D) ou tridimensionais (3D), maquete real, virtual e protótipo, entre outras; e 
i) Ação - Escolher as soluções para o produto ou processo - expressar de maneira genérica as soluções que atendem os serviços e funções esperados do produto ou processo e realizar a(s) escolha do(s) conceito(s) e idéias para essas soluções.

\section{EXPLICITAR (Meta-ação)}

\section{j) Ação - Anotar dados particulares com detalhes e transformar em informações -}

anotar dados particulares e seus detalhes para transformá-los em informações portadoras de sentido para as pessoas, de diferentes formas, através das ações anteriores;

k) Ação - Compreender e traduzir informações do produto ou processo - traduzir as informações obtidas para que se compreenda melhor o que se está propondo. Pode-se utilizar frases, ditados populares, gestos, fotografias, desenhos a mão, computador (CAD), bidimensionais (2D) ou tridimensionais (3D), maquete real, virtual e imagem mental, entre outras; e

l) Ação - Refletir as informações e as idéias para o produto ou processo - refletir, avaliar, expressar e memorizar de modo espontâneo as idéias das reflexões que surgem de forma aleatória ou simultaneamente das metas-ações e ações anteriores.

Na Figura 1 tem-se uma representação esquemática do mencionado modelo obtido no trabalho de Alves e Junior (2010).

Figura 1 - Modelo Trevo Fractal do processo.

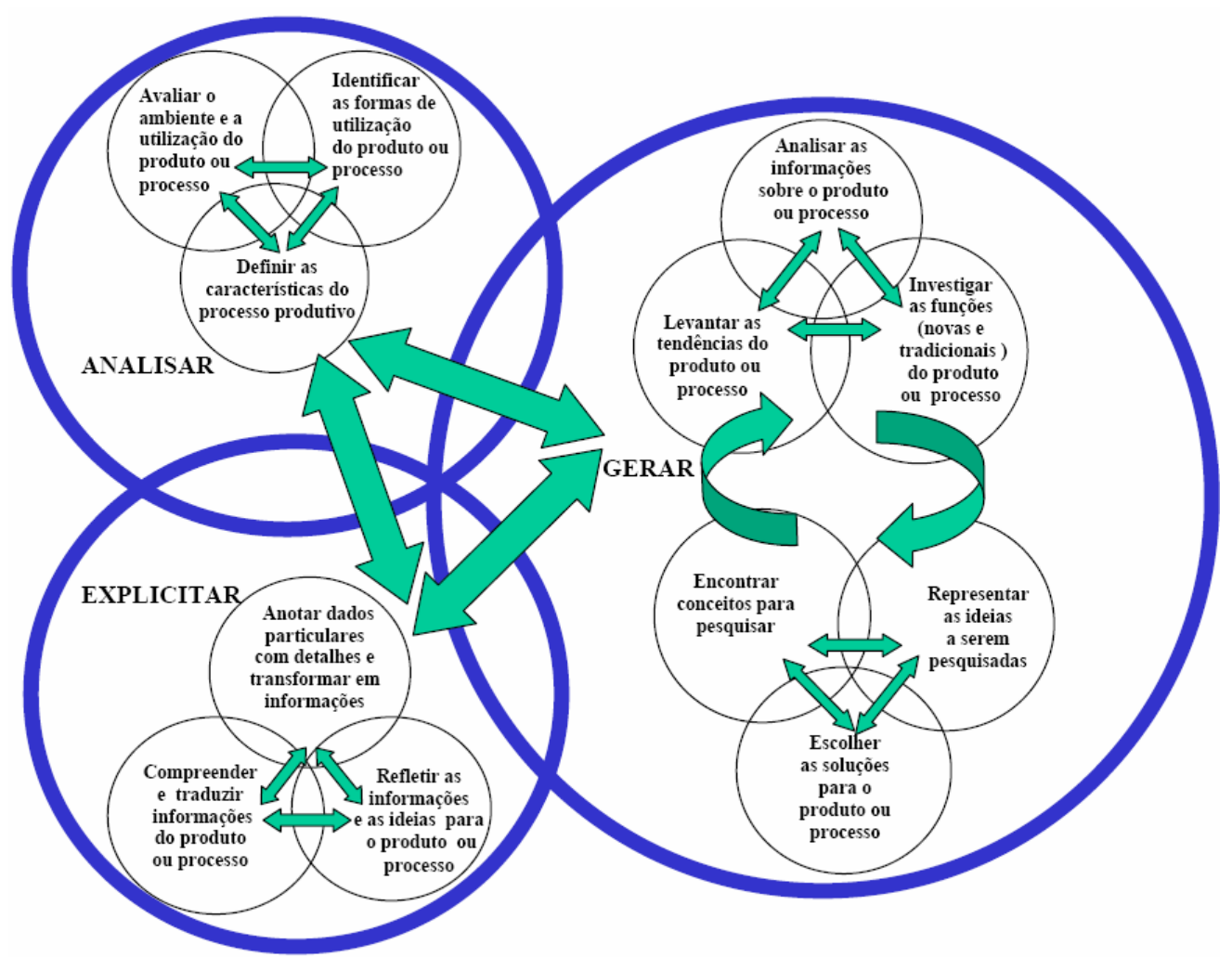

Fonte: Adaptado de Alves e Junior (2010). 
No caso específico do processo em estudo, tratando-se do departamento de tratamento de superfície e selagem onde realizam-se vedações da carroceria automotiva em aberturas e descontinuidades de chapas originadas durante as atividades de soldagem, o especialista e assim também o colaborador deste setor necessita de domínio não só do processo, mas também de várias outras habilidades como a sensibilidade constante que permite detectar qualquer tipo de anormalidade. A acuidade visual e o comprometimento com o processo deve ser alto nível e sua visão tem ser como de uma águia, sempre atento e visualizar todo e qualquer possível problema que possa gerar ao longo da produção. Tem que ter senso de perfeição como se fosse o cliente que irá adquirir o veículo e sempre pensar que uma simples falha causará uma infiltração de água, um foco de corrosão.

A seqüência do processo tem que ser executada exatamente conforme o padrão de serviço. Para isso contas-e com um manual onde descrevem-se procediemntos, onde exatamente deve-se iniciar a atividade, como deve ser feito o processo, que tipo de ferramenta deve-se utilizar e onde deve terminar o processo. Esse padrão elimina o risco de esquecimentos de atividades no processo. Nesse contexto, pode-se dizer que o domínio e a habilidade na aplicação manual são precisos, um verdadeiro sincronismo entre velocidade e técnica na inicialização e finalização da aplicação do material, eliminando totalmente as sobras e excessos de material desnecessário mantendo-se uma aparência dentro dos parâmetros da qualidade exigida e classificada.

As condições e o ritmo de produção desenvolve nos colaboradores um espírito de comprometimento naquilo que fazem. Estão sempre muito atentos às anormalidades, sempre prontos a resolver, e sempre muito comunicativos ao que diz respeito à qualidade e eficiência do processo.

A presente pesquisa fez-se necessária a partir de uma meta estipulada pelo setor de controle do departamento de pintura, onde se direciona todo à parte de controle de pessoal, produção, material primário (materiais que agregam valores diretos na produção dos veículos como, por exemplo: tinta, verniz, Sealer, pvc etc; e os secundários que são: lixas, fita crepe, papel para mascaramento etc). A meta de consumo de Sealer é 2200 gramas por automóvel, no período do estudo, e era monitorada e checada mensalmente para que não fosse ultrapassado o orçamento destinado para aquisição do material. Ressaltando que além dessa meta, existe um acompanhamento pela unidade matriz do consumo desse material, comparando as plantas mundiais da Honda automóveis para que se identifique a planta benckmark no processo e quais são suas medidas e ações para tal eficiência no processo. 


\section{Metodologia}

O estudo foi realizado no departamento de pintura que conta com um organograma interno dividido basicamente em quatro setores: $i$. pintura; $i$. tratamento de superfície e selagem; iii. preparação e pintura das carrocerias; e $i v$. reparos, inspeção e polimento das carrocerias. Este estudo está restrito ao departamento de tratamento de superfície e selagem, onde se realizam as vedações da carroceria automotiva. Trata-se de aberturas e descontinuidades de chapas originadas durante as atividades de soldagem. Para as vedações utiliza-se de uma massa de vedação de denominação Terolan $^{\circledR}$, também conhecida como Sealer. A finalidade do produto é vedar e proteger todas as aberturas contra infiltração de água, corrosão, ruído e possíveis odores. Os dados apresentados referem-se aos períodos anteriores e posteriores (junho a outubro de 2006) à implantação da modificação do ferramental (bico de aplicação do material de selagem, Terolan ${ }^{\circledR}$ ), para os dois modelos de automóveis em estudo.

Na Figura 2 apresentam-se os tipos de bicos de aplicação, antigos e novos (modificados), respectivamente. Apresentam-se também o dimensional de cada modelo de bico de aplicação e os respectivos consumos em vazão-livre por um tempo de 30s e simulações de consumo em aplicação em chapas-teste com cordões de material aplicado em $30 \mathrm{~cm}$ de comprimento. Verificou-se que a modificação do dimensional dos bicos manteve as funções de vedação, anti-corrosão, ruídos e odores. Além disso, proporcionou menores consumos do material Teloran ${ }^{\circledR}$ tanto em vazão-livre, quanto nas chapas-teste, conforme mostrado na Tabela 1.

Sabe-se que um dos modelos de automóvel (Modelo "A") montado possui 121 pontos de aplicação do material, somando um total de $74.665 \mathrm{~mm}$ lineares de material aplicado. Por sua vez, o Modelo "B", possui 84 pontos de aplicação, totalizando $58.413 \mathrm{~mm}$ lineares de aplicação do $\operatorname{Terolan}^{\circledR}$. Do montante da área de aplicação de Teloran ${ }^{\circledR}, 60 \%$ é realizada pelo chamado de "bicogrosso", 24\% pelo "bico-fino" e 16\% pelo "bico-guia".

Os montantes lineares de aplicação do material para os Modelos "A" e "B" são 75 m $( \pm 0.4$ m) e $58( \pm 0.5 \mathrm{~m})$, respectivamente. Os consumos em vazão-livre e em chapa-teste estão diretamente relacionados com o perfil da secção de cada modelo de bico e a pressão utilizada para a efetiva aplicação, sem que falhas ou bolhas nos cordões de aplicados fossem verificadas. Os consumos na vazão-livre e em chapa-teste para os três tipos de bicos foram de 4, 9, e $9 \mathrm{~g} / \mathrm{s}$ (gramas por segundo) e 10, 0,7 e 0,6 g/cm, respectivamente. Esses consumos correspondem respectivamente em torno de $3( \pm 0,5), 13( \pm 0,35)$ e $15( \pm 0,44) \mathrm{g} / \mathrm{cm} / \mathrm{s}$. A partir desses dados pode-se calcular o consumo de material em cada tipo de bico e em cada modelo de automóvel. Permite-se ainda estimar os tempos gastos em cada tipo de bico em cada modelo de automóvel. Além disso, pode-se também calcular o ganho em tempo e produtividade proporcionado por cada novo modelo de bico. 
Figura 2 - Tipos de bicos antigos e novos (modificados) com suas áreas de aplicação, dimensional e consumos de Teloran ${ }^{\circledR}$ por vazão-livre e em chapa-teste

\begin{tabular}{|c|c|c|}
\hline \multicolumn{3}{|c|}{ BICOS ANTIGOS } \\
\hline TIPO I ( BICO FINO) & TIPO II ( BICO GROSSO) & TIPO III ( BICO GUIA) \\
\hline $\begin{array}{c}\text { Aplicação (24\%): } \\
\text { Lanternas, Sahs, Portas, } \\
\text { DamperHouse e Teto } \\
\end{array}$ & $\begin{array}{l}\text { Aplicação }(\mathbf{6 0} \%) \text { : Cofre do } \\
\text { motor, Assoalho e Caixa } \\
\text { de rodas }\end{array}$ & $\begin{array}{l}\text { Aplicação(24\%): Portas, } \\
\text { Capô e Porta-Malas }\end{array}$ \\
\hline $1,5 \times 2(\mathrm{~mm}) \Gamma$ & $2,5 \mathrm{~mm}$ & $\begin{array}{l}1,5 \times 6 \\
(\mathrm{~mm})\end{array}$ \\
\hline $\begin{array}{l}\text { Vazão-livre: } 120 \mathrm{~g} \\
\text { Chapa-teste: } 30 \mathrm{~g}\end{array}$ & $\begin{array}{l}\text { Vazão-livre: } 260 \mathrm{~g} \\
\text { Chapa-teste: } 21 \mathrm{~g}\end{array}$ & $\begin{array}{l}\text { Vazão-livre: } 270 \mathrm{~g} \\
\text { Chapa-teste: } 20 \mathrm{~g}\end{array}$ \\
\hline \multicolumn{3}{|c|}{ BICOS NOVOS (Modificados) } \\
\hline TIPO I ( BICO FINO) & TIPO II ( BICO GROSSO) & TIPO III ( BICO GUIA) \\
\hline $\begin{array}{l}\text { Aplicação: Lanternas, } \\
\text { Sahs, Portas, } \\
\text { DamperHouse e Teto }\end{array}$ & $\begin{array}{l}\text { Aplicação: Cofre do } \\
\text { motor, Assoalho e Caixa } \\
\text { de rodas }\end{array}$ & $\begin{array}{c}\text { Aplicação: Portas, Capô e } \\
\text { Porta-Malas }\end{array}$ \\
\hline $\begin{array}{l}1,0 \times 1,2 \\
(\mathrm{~mm})\end{array}$ & $\begin{array}{l}0,75 \times 6 \\
(\mathrm{~mm})\end{array}$ & $\begin{array}{r}0,75 \times 7 \\
(\mathrm{~mm})\end{array}$ \\
\hline $\begin{array}{l}\text { Vazão-livre: } 105 \mathrm{~g} \\
\text { Chapa-teste: } 9 \mathrm{~g}\end{array}$ & $\begin{array}{l}\text { Vazão-livre: } 157 \mathrm{~g} \\
\text { Chapa-teste: } 12 \mathrm{~g}\end{array}$ & $\begin{array}{l}\text { Vazão-livre: } 158 \mathrm{~g} \\
\text { Chapa-teste: } 12 \mathrm{~g}\end{array}$ \\
\hline
\end{tabular}

Fonte: Autoria Própria (2009).

\section{Resultados e Discussões}

Na Figura 3 exibe-se uma comparação entre os consumos para os bicos antigos e novos para aplicação de Teloran $^{\circledR}$ na vedação de todos os pontos de junção entre chapas nos Modelos de automóveis " $\mathrm{A}$ " e "B". Para os três bicos antigos, observa-se que o para modelo "A" apresenta um consumo de 4.939 gramas enquanto que no Modelo "B", o consumo atinge 3.800 gramas.

A diferença entre os consumos dos dois modelos pode ser explicada pela diferença na metragem de aplicação entre os dois modelos, 75 e 58 metros, respectivamente. Em contra partida, depois da modificação do design dos três bicos de aplicação, obtiveram-se significativas reduções nos consumos do material Terolan ${ }^{\circledR}$ expressa em gramas/carro. 
Figura 3 - Comparação entre os consumos em gramas/carro de Teloran ${ }^{\circledR}$ para os bicos antigos e novos: (a) Modelo de automóvel "A" e (b) Modelo de automóvel "B".

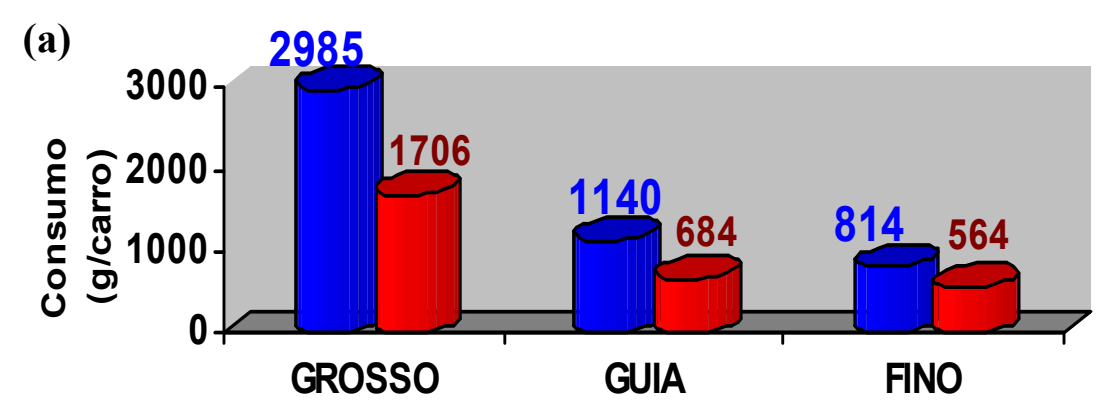

Bicos antigos $\square$ Bicos novos

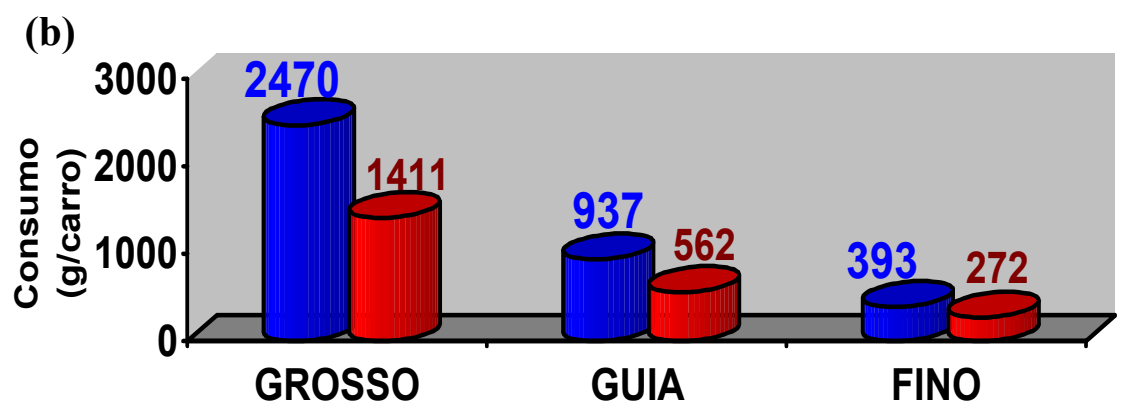

Bicos antigos $\square$ Bicos novos

Fonte: Autoria Própria (2009).

Na Figura 4 exibem-se os dados coletados para acompanhamento da variação de consumo diário de Teloran ${ }^{\circledR}$ num período de 60 dias que consistiu em meados de agosto para setembro de 2006. Nesse período registrou-se um rendimento de 106 carros (entre os dois modelos) utilizando-se uma massa de $250 \mathrm{~kg}$ do material Teloran ${ }^{\circledR}$. Um consumo médio de $2,4 \mathrm{~kg} /$ carro foi determinado, porém é um valor que encontra-se levemente acima daquilo que a planta da fábrica pretendia como meta para o período correspondente. Atualmente esses valores apresentam-se consideravelmente melhorados em torno de $20 \%$ destes apresentados.

Na Figura 5 demonstram-se as reduções obtidas em R\$/carro após implantação dos novos dimensionais de bicos de aplicação. Com os antigos bicos de aplicação os consumos em massa de $\operatorname{Terolan}^{\circledR}$ eram 4,9 kg e 3,8 kg para os Modelos de automóveis "A" e "B", respectivamente. Com os novos bicos de aplicação esses valores reduziram significativamente, atingindo $60 \%$ de redução em ambos casos, isto é, consumos de $3 \mathrm{~kg}$ (2.954g) e $2 \mathrm{~kg}$ (2.245 g), respectivamente. Para os bicos antigos os gastos ou custos de Terolan ${ }^{\circledR}$ por unidade produzida eram $\mathrm{R} \$ 39,19$ e $\mathrm{R} \$ 30,13$ para os 
Modelos de automóveis "A" e "B". Com as reduções em torno de 60\%, R\$23,42 e R\$17,80 passaram a ser os valores dos custos de Terolan ${ }^{\circledR}$ por unidade produzida, respectivamente.

Figura 4 - Comparação entre os consumos em gramas/carro de Terolan ${ }^{\circledR}$ para os bicos antigos e novos: (a) Modelo de automóvel "A" e (b) Modelo de automóvel "B".

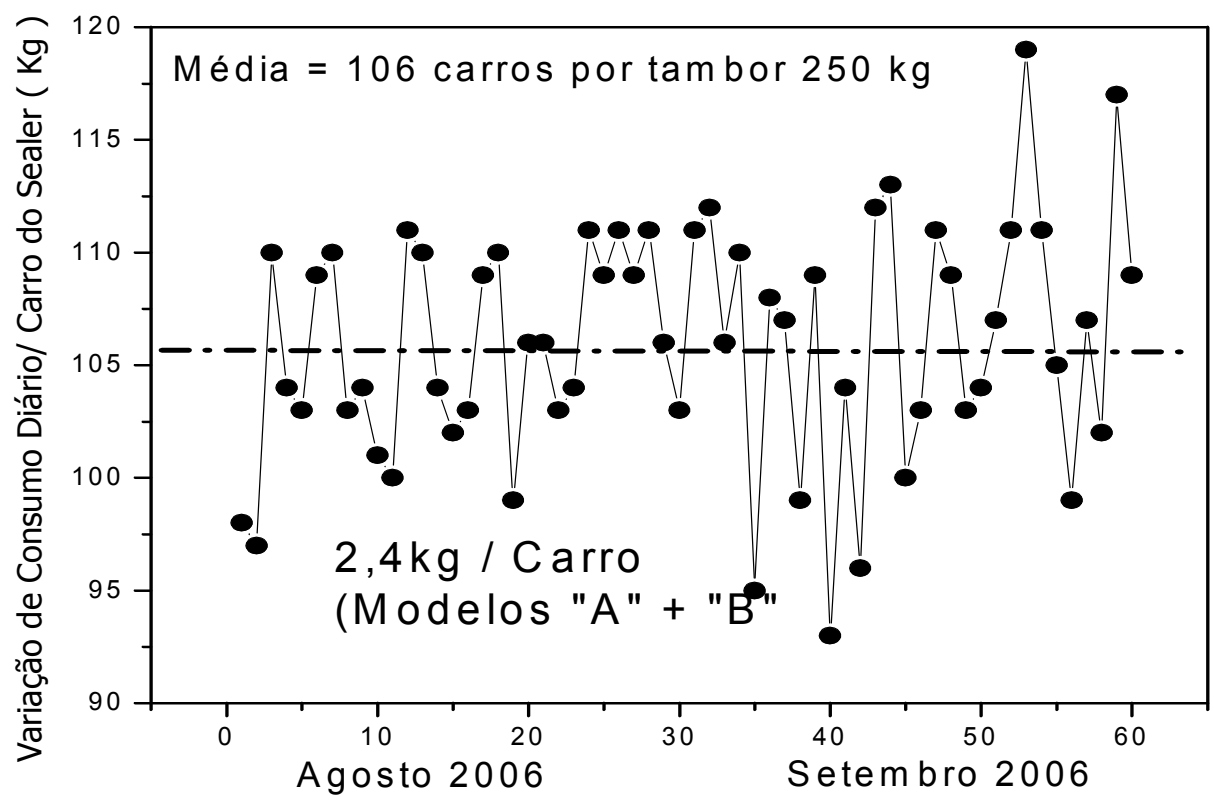

Fonte: Autoria Própria (2009).

Figura 5 - Comparação entre os custos em R \$/carro de Terolan ${ }^{\circledR}$ para os bicos antigos e novos para os modelos de carro "A" e "B".

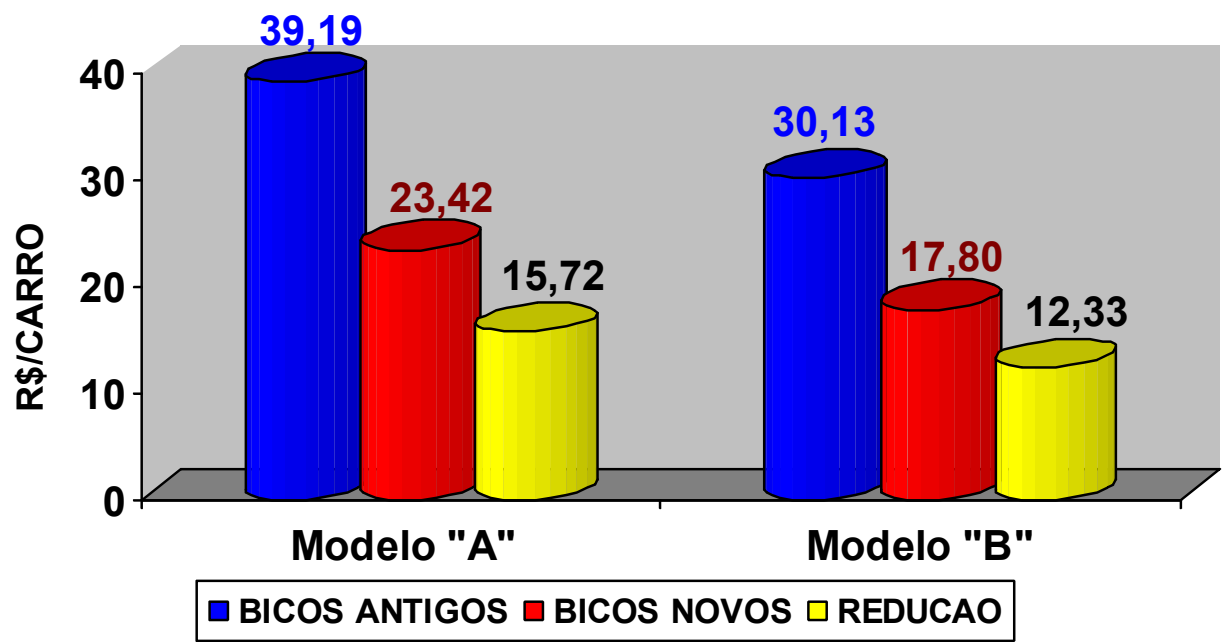

Fonte: Autoria Própria (2009). 
No que diz respeito às unidades produzidas, até a elaboração deste artigo a planta da montadora em estudo apresentava uma produção diária de 315 unidades entre os dois modelos, trabalhando no que se pode dizer em três turnos e com produções em lotes.

Utilizando-se das 315 unidades diárias como base de cálculo, tem-se em uma produção anual de 63.000 unidades (que consiste em média em 200 dias de trabalho). Com as significativas reduções nos consumos do material Terolan $^{\circledR}$ por intermédio das modificações nos bicos de aplicação, uma grande vantagem lucrativa foi atingida. Pode dizer que se deixou de gastar em torno de R 650 mil/ano, sendo deste montante, em torno de $\mathrm{R} \$ 370$ mil para o modelo de carro "A" e R\$280 mil para o modelo "B", conforme mostrado na Figura 6.

Considerando-se que na fase de elaboração deste artigo, a planta da montadora passou por diversas modificações de melhoria no intuito de aumentar a capacidade de produção. Pode-se dizer que a capacidade de unidades diárias de automóveis quase que dobrou de valor entre os anos de 2008 e 2009 e provisiona-se mais aumentos para o próximo biênio (2010 e 2011). Assim, utilizando-se dos cálculos e valores apresentados, pode-se também fazer uma projeção para as possíveis economias já atingidas desde a implantação desses novos modelos de bico de injeção, permenado pelos dias atuais até o próximo biênio. Salienta-se dizer ainda que a empresa apresenta um programa de valorização de seus colaboradores e esses mostram-se efetivamente comprometidos com a empresa, participando nos programas de reduções de custos e melhorias de produtividade. Pode-se dizer que desde a inauguração da montadora no Brasil, um programa de melhoria contínua tem sido desenvolvido desde então.

Figura 6 - Valores economizados nas produções mensal e anual para os Modelos de automóveis “A” e "B" devido às reduções em R $\$$ /carro com a implantação dos bicos novos.

Produção diária: 315 unidades

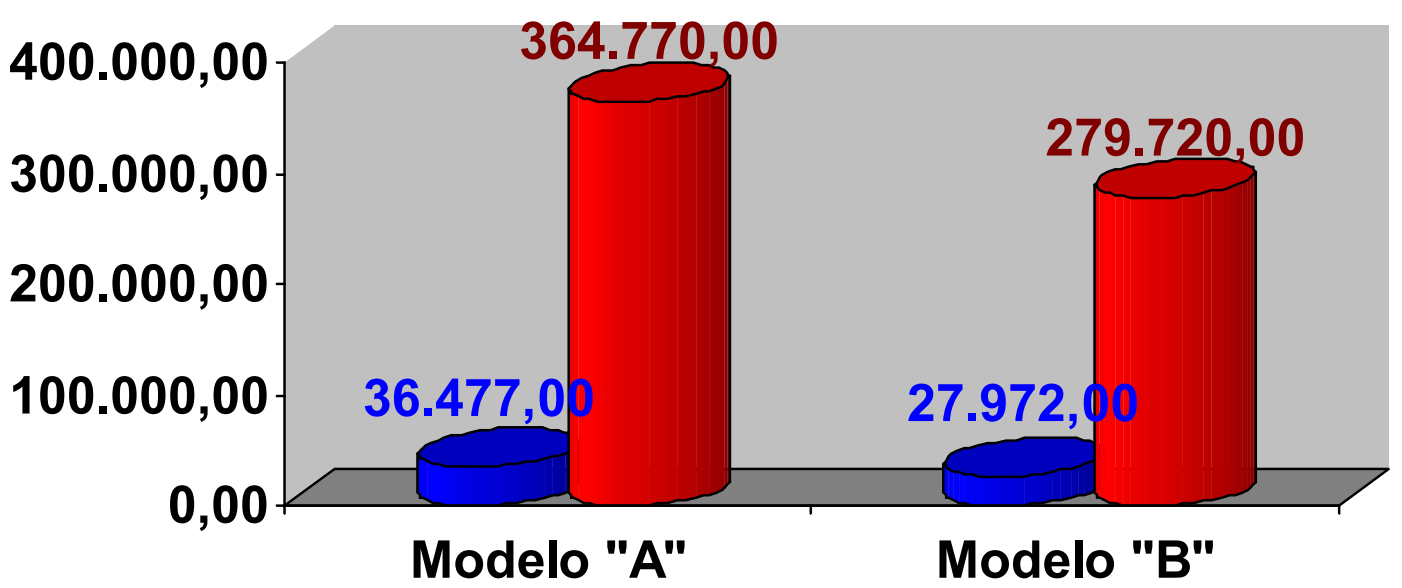

口 PRODUÇÃO MENSAL 20 DIAS (6.300 UNIDADES) $\square$ PRODUÇÃO ANUAL 200 DIAS (63.000 UNIDADES)

Fonte: Autoria Própria (2009). 
Com isso, em concordância ao que foi reportado por Braga e colaboradores (2008), tem-se a melhoria da qualidade final do produto, aumento da produtividade, redução de custos e otimização dos processos. O investimento na capacitação e reconhecimento dos colaboradores chega a ser desprezível, quando são computados os retornos financeiros oriundos de reduções expressivas de custos de produção e manufatura, como exemplo típico disso, tem-se os resultados apresentados neste artigo.

Acredita-se que diante da crise econômica que atualmente aflige às empresas, a valorização do capital humano ainda é uma ferramenta de gestão que sempre que semeada, "frutificará" consideráveis resultados. Porém, há empresas que diante de um empecilho qualquer, primeira coisa a fazer é a redução de quadro de funcionários e extinção dos programas de incentivos. No mercado econômico e globalizado que se tem daqui para diante, aqueles que não "cultivarem" e prepararem bem seus "solos", terão que assistir a frutífera colheita dos concorrentes que ao "solo" bem preparam.

\section{Considerações Finais}

O estudo realizado na montadora automobilística da Região Metropolitana de Campinas teve um resultado positivo e significativo ao departamento de Pintura e ao setor de selagem de carrocerias. Toda a abordagem do problema do alto consumo do material de vedação (Terolan ${ }^{\circledR}$ ) teve uma linha de raciocínio sistêmica que permitiu chegar aos resultados mostrados neste estudo.

Assim, deixou-se de gastar uma cifra em torno de $\mathrm{R} \$ 650 \mathrm{mil} / \mathrm{ano}$, em decorrência da modificação do design dos bicos de aplicação para selagem de carrocerias de dois diferentes modelos de automóveis. Talvez alguns leitores possam pensar que R $\$ 650$ mil ao ano não seja uma redução significativa para uma empresa do porte tal qual possui a montadora em estudo. Contudo, deve-se lembrar que inúmeras operações e processos compõem a produção dos modelos atualmente montados. Se todas as seções ou departamentos tomarem uma única operação, atividade ou processo sistematicamente com intuito de reduções de custos e desperdícios, vultosas serão as cifras atingidas.

Neste artigo, os autores não tiveram como objetivo simplesmente exibir os resultados expressivos atingidos no desenrolar do testudo, mas também despertar aos gestores que atenções especiais devem ser dadas às linhas de atividades do processo, seja de um produto tangível ou intangível, aos colaboradores que interagem bem mais diretamente com o processo em si que qualquer outra pessoa ou gestor. Ouvindo e preparando esses colaboradores, tratando-os dignamente com humanismo e profissionalismo, que deve ser o "papel” fundamental de um bom 
gestor, as famosas filosofias de melhoria contínua e rentabilidades certeiras serão atingidas em curtos intervalos de tempos com menores esforços. Além disso, pode destar ainda que as melhorias apresentadas foram provenientes de ações originadas de um processo criativo, por meio de caminhos aleatórios, embora as pessoas envolvidas no processo tiveram intensa participação, expondo as dificuldades encontradas utilizando o ferramental, dispositivos e interagindo com $o$ layout que anteriormente existia. Similarmente ao que foi observado por Alves e Junior (2010), podese dizer que sem a utilização de ferramentas específicas foi possível fornecer liberdade de criação aos colaboradores envolvidos no processo em estudo, propiciando-se melhoria e satisfação de todos envolvidos. Em consonância ao que também foi reportado por Alves e Junior (2010), houve e será sempre propiciado um estímulo ao desenvolvimento de novas maneiras de se fazer mais com menos, potencializando-se a redução de custos e a simplificação de processos, para novas utilizações dos produtos e processos (ALVES e JUNIOR, 2010).

\title{
Agradecimentos
}

Os autores agradecem todo o apoio dado pelos colaboradores e gestores da HAB, Honda Automóveis Brasil, Sumaré e pelas informações fornecidas quando solicitadas. Agradecimentos também são direcionados ao aporte financeiro provindo das Faculdades Network, Sumaré, SP.

\begin{abstract}
The present article aims to show a case history concerning to the manufacturing cost reduction attained by changes in the design of the sealer Terolan ${ }^{\circledR}$ application. This material is widely used in the department of painting during assembling and manufacturing processes into a famous automobile assembler located at Metropolitan Region of Campinas cit (Honda Automobile Brazil Co.). It was found that in the white-body production for two different vehicle models, an financial amount of about $\mathrm{R} \$ 650,000$ per year can be economized. This considerable decrease in production costs (of about $60 \%$ ) can be attributed to decreasing in the consumption of the Terolan ${ }^{\circledR}$ material due to new designs of the tip material application devices. Furthermore, the present authors suggest that some techniques such as brainstorming, empowering and human capital valorization activities can significantly provide a more competitiveness advantages.
\end{abstract}

Key-words: Manufacturing cost reduction, Raw material, White-Body, Automobile production.

\section{Referências}

ALBERTI, P. Stimuler la criatividade par la mise à disposition de la connaisance capitalisée. Paris, 2006. Thèse, (Doctorat em Génie Industriel) - Ecole Centrale Paris, Paris, 2006b

ALVES, A.C.; JÚNIOR, A. B. Melhoria de um processo produtivo utilizando como referência um modelo do processo criativo na solução. Revista Gestão Industrial, v. 6, n. 1: p. 177-197, 2010 
BRAGA, L.P., SANTOS, P.R.G.;OLIVEIRA, E.A. A.Q. Análise da implantação do processo de melhoria contínua na indústria automobilística. Tecnologia em Metalurgia e Materiais, v. 5, n. I, p.60-64, jul.-set. 2008.

CERRA, A. L.; MAIA, J.L. As atividades de desenvolvimento de produtos de três montadoras de motores para automóveis - estudos de caso no setor automobilístico brasileiro, Revista Gestão Industrial, v. 02, n. 01, p. 01-12, jan.-mar. 2006.

CHEN, I.; PAULRAJ, A.; LADO, A. Strategic purchasing, supply management, and firm performance. Journal of Operations Management, Amsterdam, v.22, n.5, p.505-523, Oct. 2004.

crossef

CRUZ, T. Sistema, organização \& métodos: estudo integrado das novas tecnologias de informação / Tadeu Cruz. $-2^{\circ}$ ed. - São Paulo; Atlas, 2002.

GAITHER, N.; FRAZIER, G. Administração da Produção e Operações. 8.a ed. São Paulo;Thomson Learning Pioneira, 2004

JIRO, K. The original KJ Method. Tóquio: Kawakita Research Institute, 1991

KUNIGAMI, F. J., OSÓRIO, W.R. Gestão no controle de estoque: estudo de caso em montadora automobilística, Revista Gestão Industrial, v. 05, n. 04: p.24-41, 2009

LIMA, C.S.; OSÓRIO, W.R. Case history de redução de matéria-prima em montadora automotiva por modificação de design ferramental. Revista de Administração (Faculdades Network), v. II, Ano II, n. 1, p. 109-114, 2008.

MARTINS, P. G. e ALT, P. R. C. Administração de materiais e recursos patrimoniais, 1 ed., $5^{\text {a }}$ t tiragem, São Paulo; Saraiva, 2003.

MARTINS, P G.; LAUGENI, F P. Administração da Produção. São Paulo: Saraiva, 2001.

MOREIRA, D. A. Administração da Produção e Operações. São Paulo: Pioneira Thompson Learning, 2002

OSBORN, A. F. Applied imagination. New York: Charles Scribner's Sons, 1953.

OSÓRIO, W.R., GARCIA, M. BRITO, F. Software de Averiguação do Nível de Alinhamento da Competência Profissional de Colaboradores em Sistema Produtivo. Revista Administração (Faculdades Network), Brasil, v. I, n. 1, p. 41-50, 2004.

PARNES, S. J. Source book for creative problem solving. New York: Creative Education Press, 1992.

PLSEK, P. E. Creativity, innovation, and quality. Milwaukee: Quality Press, 1997

RODRIGUES, D. M.; SELLITTO, M.A. práticas logísticas colaborativas: o caso de uma cadeia de suprimentos da indústria automobilística, Revista de Administração (R. Adm), São Paulo, v.43, n.1, p.97-111, jan./fev./mar. 2008

ROSSMAN, J. The psychology of the inventor: a study of the patentee. Whashington: Inventor's Publising, 1931.

SLACK, Nigel. Administração da produção / Nigel Slack, Stuart Chmbers, Robert Johnston; tradução Maria Teresa Corrêa de Oliveira, Fábio Alher; revisão técnica Henrique Luiz Corrêa. - $2^{\circ}$ ed. - São Paulo; Atlas, 2002.

SLACK, Nigel. Vantagem competitiva em manufatura: atingindo competividade nas operações industriais / Nigel Slack ; tradução Sônia Maria Corrêa ; revisão técnica Henrique Luiz Corrêa. - 2º ed. - São Paulo; Atlas, 2002

TUBINO, D.F. Manual de planejamento e controle da produção, SP. 2a . Ed. Atlas, 2004.

, D.F. Sistemas de produção: a produtividade no chão de fábrica. Porto Alegre, 1999.

WALLAS, G. The art of thought. Nova York: Harcourt, 1926. 


\section{Dados dos autores:}

\section{Cleisson Soares Lima}

Honda Automóveis Brasil Ltda, HAB

Supervisor/Colaborador em Desenvolvimento de Processos

Endereço: Av. Ampélio Gazzetta, 2445, 13460-000, Nova Odessa, SP, Brazil

Telefones para contato: (55) 1935213319 ou 1991500988

e-mail: cleisson lima@hondabr.com.br

\section{Fabrício Palma Braga}

Honda Automóveis Brasil Ltda, HAB

Supervisor de Produção na Honda e Coordenador do Curso Técnico de Logística nas Faculdades Network, Campus Sumaré, SP

Endereço: Av. Ampélio Gazzetta, 2445, 13460-000, Nova Odessa, SP, Brazil

Telefones para contato: (55) 1935213319 ou 1991500988

e-mail: fabricio braga $@$ honda.com.br

\section{Wislei Riuper Osório}

Faculdades Network e UNICAMP, Universidade Estadual de Campinas

Administração e Engenharia de Materiais

Coordenador Interino do Curso de Administração, Pesquisador Colaborador

Endereço: Av. Ampélio Gazzetta, 2445, 13460-000, Nova Odessa, SP, Brazil

Telefones para contato: (55) 1934662527

e-mail: $\underline{\operatorname{adm} @ \text { nwk.edu.br }}$ 